\title{
MAŁŻEŃSTWO I RODZINA W NAUCE I PRAKTYCE DUSZPASTERSKIEJ ŚW. AUGUSTYNA
}

Sw.Augustyn jest jedynym z lacińskich 1 greckich 0jców Kośc10za, który małzeństwu pośrięcil synteze dogmatyczna 1 moralna ${ }^{1}$. Biskup Hippony swej nauce o małzeństwie zachował złoty środek między manichejską pesymistyczną ocena tego zwiazku², a bardzo optymistycznym wartó́ciowantem małzeństwa proponowanym przez Jowiniana ${ }^{3}$, ustrzegajac sie rómniez hieronimianskiego dawania tylko dyspensy na małzeństwo, jaka znajdujemy u wielkiego egzegety $w$ polemice z Jowintanem ${ }^{4}$. Mazzeristwo dla Augustyna jest dobrem. Swięty wskazuje na źródło owego dobra od etrony ludzi kierowanych oczywiście przez Boga. C6ź Jest tym źródłem? "Kazdy człowiek jest częscia rodzaju ludzkiego, a natura ludzka będąc społecznq ma wielka 1 naturalną wartość siłe przyjaźni"5. Waśnie owa przyjaźn podnosi wartość człowieczenistwa, gdy zwlazek przyjacielski jest wartosela godna pozadania sama w sobie. Augustyn urypukla teze, ze przedmloten jego rozwazá́ jest dobro małzeńsk 10 po grzechu piermorodnym ${ }^{6}$. Bóg sam sprawtı, zo przyjaźn 1aczaca małzonków ma ostateczności wspólne pochodzenie - jednego pra-

1 Por. De continentia, PL 40,349-372, CSEL 41,141-183; De bono coniugali, PL 4:0,373-396, CSEL 41,187-230; De aduiterinis coniugi1s, PL 40,451-486, CSEL 41,347-410; De bono viduitatis, PL 40,429-450, CSEL 41,305-343; De nupt1is et concupiecientia, PL 44,413-474, CSEL 42, 209-319.

2 De natura bon1 46, CSEL 25,2, 884-886/eragment 11stu Menesa/; De moribus Ecclesiae catholicae et de morlbus manichasorum II, 19-20, 54,65,68, PL 32,1353-1354, 1368, 1372-1374; Confesstones $V, 3-14$, CSEL 33, 90-112, t tur. Z.Kub1ak/Swlęty Augustyn, Wyznania, Warszawa $1882^{2} / 69-85$.

3 Do haeresitus 82 , PL $42,45-46$.

4 Hieronymus, Contra Jovinianum I 7, PL 23, 218-221.

5 De bono conlugali 1, CSEL 41,187, tłum. W.Eborowicz/Sw.Augustyn, Wartości mazteŕstwa, Pelplin 1980, Pro familia $1 / 51$.

6 Tamze 3, CSEL 41,190, Eborowicz 54. 
ojca rodzaju ludzkiego. I to jest właśnie godne uwagi, że ów monogenizm jest źródłem wielkiego dobra wspólnej przyjaźni. Augustyn posuwa się jeszcze dalej głosząc, że małżeństwo jest dobrem samym w sobie. Na dowód tego powołuje się na Pismo św., które świadczy o dobru małżeństwa przez potwierdzenie jego nierozerwalnosci. Zbawiciel ze swej strony uświęcił małżeństwo będąc na godach w Kanie Galilejskiej ${ }^{7}$. I właśnie z tego Paktu, że małzeństwo jest dobrem samym w sobie, odznaczajacym się siłą przyjaźni, pochodzą trzy wartości tego zwiazzku: potomstwo, wierność i sakrament, które są znane 1 przypomniane $w$ dwóch encyklikach papieskich minionego cza$\mathrm{su}^{8}$. Za pierwszym $z$ tych dóbr przemawia Pismo św. /1 Tm 5,14/, a biskup Hippony odwołuje się w tym względzie do powszechnej zgody rodzaju ludzkiego, eksponującego ten cel zwiazku małżeńskiego: "Małżeństwo u wszystkich ludów ma ten sam cel - zrodzenie potomstwa" ${ }^{\text {. }}$ Wartość potomstwa, jak sądzimy, będąc przejawem siły przyjaźni, jest celem związku małźeńskiego w znaczeniu fizycznym, społecznym, praktycznym i filozoficznym.

Druga wartościa małżeństwa jest dobro wierności, o którym tak pięknie wypowiedział się Augustyn: "Gdy ustaje przyjaźn, nie zachowuja się więzy ani małzeństwa, ani pokrewieństwa, ani powinowactwa, bo wich oczywiście istnieje przyjacielska zgodność"10. Uzasadnieniem dobra wierności jest samo małźeństwo. Dla powstania małżeństwa obie strony muszą mieć wole nie łączenia się związkiem doraźnym na "pewien czas", ale zawarcia małżéstwa na całe życie ${ }^{11}$, poprzez zewnętrzne wyrażenie swej zgody na małżeństwo, choé św. Augustyn - jak sądzimy - uznawał za wystarczajace nawet pośrednie ujawnienie woli małżonków. Z wartościa wierności łączy się zagadnienie poligamii patriarchów. Zdaniem biskupa Hippony wielożeństwo patriarchów nie było wykroczeniem przeciw naturze, gdyż patriarchowie współżyli ze swymi kobietami "mając na celu rodzenie

\section{$7 \quad$ Tamże.}

8 Leon XIII w 1880 r. - "Arcanum divinae sapientiae", i w 1930 r. Pius XI "Casti conubii".

9 De bono coniugali 19, CSEL 41,212, Eborowicz 71 .

10 De fide rerum quae non videntur 4, PL 40,173; por. Le bono coniugali 4, CSLL 41, 191-192.

11 Por. De bono coniugali 16, CSEL 41, 208-209, Eborowicz 68-69. 
potomstwa"12. Dopatrywaz sie ponadto zarówno u patriarchów, jak 1 u 1ch małzonek wysokiego stopnia róznych cnót. Było to dlatego mozliwe, ze "Ojcowie zyjac małzeństwie proroczym pragnęl1 tylko potomstwa, a nim wyłacznie przygotowania przyszłego Wcielenia Chrystusa"13. Nie mozna zapominać również o zawartej tamze polemice $z$ manichelzmem ponizającym patriarchów właśnie z powodu ich wielozeństwa.

Trzecim wreszcie dobrem małzeństwa chrześcijańskiego jest Jego sakramentalność utoźsamiająca się - zdaniem Augustyna - z jego nierozerwalnością ${ }^{14}$. Chcąc się zapoznać z augustyńską nauką o małzeństwie jako sakramencie, powinniśmy wspomnieć o jego pogladach na sakrament ogólności. Sakrament zaś według Augustyna, jest "świętym znakiem"15, a znak dla biskupa Hippony jest tym, co "obok tego, ze wyciska swoja formę w zmysłach, jest czymś, co samo przez sie przywodzi na myśl coś innego"16. Lącząc obie poprzednie wypowiedz1 Augustyna dochodzimy do tego, ze sakrament według niego jest znakiem odnoszącym się do rzeczy Bożych ${ }^{17}$. Biskup IIippony wyróżnia w swym określeniu sakramentu pierwiastek materialny, zwany znakiem 1 rzecz - moc sakramentu ${ }^{18}$. Autor dzlełka "De bono coniugali" uznaje, ze małzeństwo jest znakiem jedności łączącej w szczególniejszy sposób małżonków zjednoczonych z Głowa ciała mistycznego, którego są oni członkami spełniającymi szczególną funkcję ojców i matek. Swój zaś pogląd, ze małzonkowie są znakiem wyżej wskazanego zwiazku, zachodzacego między członkami Ciała mistycznego a jego Głowa, opiera

12 De bono contugali 33, CSEL 41,228, Eborowicz 84 .

13 Tamźe 34, CSEL 41,229, Eborowicz 85.

14 Tamze 7, CSEL 41, 196-197, Ebor owi cz 59-60.

15 De civitate Dei X 5, CSEL 40,452, tłum. W.Kornatowski/Swięty Augustyn, 0 państwie Bozym, t.1-2, Warszawa 1977/, t.1, 447: "Widzialna tedy ofiara jest sakramentem, to jest śriętym znakiem ofiary ntewidzialnej".

16 De doctrina christiana II $1, \operatorname{CCL} 32,32$, tłum. J.Sulowsk1/Ŝw. Augustyn, 0 nauce chrześcijańskiej. Sprostowania, Warszawa 1979, PSP 22/40.

17 Por. Epistola 138,7, CSEL 44,131, PL 33,527.

18 In Johannis evangelium tractatus 26,12, CCL 36,265-266, tłum. W.Szoldrsk1/Sw.Augustyn, Homilie na ewangelie.1 pierwszy list św.Jana, Warszawa 1977, PSP 15/, 374-375. 
na Pr 47,2 1 na swej doktrynie o Ciele mistycznym. Z jego lektury wynika,ze skutkiem sakramentalnośc1 tego zwiazku jest jego nierozerwalność a nie łaska, o której nie wspomina, 1 tę waśnie skuteczność musimy uznać za zasadnicza naukę Augustyna o skutku małzeństwa. Zachomanie jednak tej nierozermalnośct z powodu słabości ludzkiej wymaga pomocy Bozej. "Moim zdaniem - pisze Augustyn - zwiazek mazzeński nie miałby takiej mocy, jeśli mzlác pod uwage słabość ludzka, gdyby mu jej nie udzieliła wyzsza rzeczywistość za pośrednictwem pewnego sakramentu"19. Z traktatu "De ride et operibus"20 oraz z dziela "De nupti1s ot concupiscientian'21 wynika, ponadto, zo dla Augustyna nierozerwalność jest skutkiem sakramentalności tego zwiazku, zachowywana jednak dzięki pomocy "wyzszej rzeczywistośc1" za pośrednictwem pewnego sakramentu.

Przeciw vartości potomstwa wymienionym dziełku "De bono conlugali" sklerowane jest nienaturalne współzycie małzonków, które Augustỵn uwaza za grzech cięzki ${ }^{22}$. Swój zás surowy sąd o takich stosunkach uzasadnia przez odwolante sie do Rz 1,26-27. Rozumowa racja krytyk1 tak1ego współzycia jest nienaturalny sposób obcowania, sprzec1wiający się zrodzeniu potomstwa. Cudzołóstwo sprzecimia sie bardzo -1elkiemu dobru wierności małzeńskiej, w obronte której nalezy poswięc1c zdrowie 1 zycie. Podaje on nastepujaca definicje tego wystepku: "Naruszanie tej wierności nazywa się cudzołóstwem. Dokonuje sie ono wówczas, gdy wbrew ugodzle małzeńskiej, pod mpływem młasnej, czy cudzoj naniętnośc1, kobieta wopbłzyjo z innym męzczyzna lub męzczyzna z Inna kobietąn23. Biskup Hippony kwalifikuje cudzolóstmo jako grzoch c1ęzk1, którego nie uzasadnia nawet niopłodność zony 24 . Etyka małzeńska ujeciu Augustyna jest przede wszystkim pozytywna 1 to tek dalece, zo przypisuje małzeństwu nio tylko moc mypromadzenta dobra ze zła pozqdilwości, ale nawet dostrzega pozadliwości powne dobro czerpane z małzeństwa. y ziazku z tym otaczail on pasterska

19 De bono contugali 7, CSEL 41,197, Eborow $1 \mathrm{Cz} 59$.

20 De Pide et operibus $7,10, \mathrm{PL} 40,203$.

21 De nupt11s ot concupiscient1a I 11, CSEL 42,222-223.

22 De bono coniugali 12, CSEL 41,317, Eboromicz 65.

23 Do bono con1ugal1 4, CSEL 41,191-192, Eborouicz 55.

24 Por. De bono contugali 7 , CSLL 41,196-197, Eborowicz 59. 
troską swoich namiętnych rodaków, którym "niezmordowanie próbowal nałozyć prawo chrześcijańskie wraz z jego subtelnościami 1 surowościan" ${ }^{25}$, 1 stąd pewien jego rygoryzm był uzasadniony. Czy Augustyn bliżej przekazal nam post źpowante małzonków 1 swoje duszpasterskie Fysiłk1 na odcinku ówczesnych rodzln? smych niezrównanych "Wyznaniach" przedstawiz nam obraz rodziny, z której wyszedł. Jego rodzice Patrycjusz 1 Monika byli, posługujac oi dzisiejsza torminologia. małżeństwem mieszanym. Patryojusz bowiem - pisał Augustyn - został katechumenem "w owym szesnastym roku mojego zycia"26. W pięknym zaś wspomnientu pośrięconym swej matce pisał o jej staraniach, by mąz został chrześcijaninem: "Wreszcie i meza masnego u schyłku jego zycla doczesnego pozyskaza dia Ciebie[Boze] "27. Przedstawiajac natomiast swe studia Kartaginie pisal, ze przy ksztazceniu stylu "na takı waśnie cel łozyła środki materialne moja matka w owym dzieตiętnastym roku mego zycia, gdy ojciec juz od dwóch lat nie zył"28. Patrycjusz umarł jak s1e zdaje, piermszym roku pobytu Augustyna - Kartaginie czyl1 $369 / 370 / 1$ lub 371 roku ${ }^{29}$. Augustyn mspomina ponadto, zo mial brata Nawigiusza ${ }^{30}$ oraz siostre ${ }^{31}$. Patrycjusz, mimo ze obciązały go grzechy niewiernośc1 małzeńskiej ${ }^{32}$, dbal o swe dzleci, zabiegając w szczególny sposób ze wględów ambicjonalnych ${ }^{33}$ - wyzsze wykształcente i śwletniejoza przyszłość dla swego syna Augustyna. Niewiele natomiast zabiegax o moralno-religijne wychowa-

25 P. de Labriolle - G.Bardy, Histolre de la littérature latine chrétienne, t.2, Par18 ${ }^{3} 1947,638$.

26 Confessiones II 3 , CSEL 33,33, Kub1ak 26.

27 Confessiones IX 9, CSEL 33,215, Kubiak 166.

28 Confessiones III 4, CSEL 33,48-49, Kubiak 37.

29 P.Brown, La vie de saint Augustin, trad.J.H.Marrou, Paris 1971, 12.

30 Por. De vita beata 6,7,14, PL 32,962,963,966, ¿łum. A.Swiderkówna /Swiegty Augustyn, Dialogi Pllozorlczne, $\hat{t} .1-4$, Warszawa 1953$1954 \%, .1,13,14,22$; Confessiones IX 11, CSEL 33,218 , Kubiak 168-169.

31 Por. Epistola 211,4, PL 33,959, CSEL 57, 358-359.

32 Por. Confessiones IX 9, CSEL 33,213, Xubiak 164.

33 Por. Confessiones II 3,6, CSEL 33,32-34, 38-40, Kublak 26-28, 30-31. 
nie syna pozostakiając je matce, która wzorowo spelniała te obowlazk1: "Od samego urodzenta zegnano mnie znakiem Jego/Chrystusa/ 1 kosztowałem Jego sol1. Bo matka goraco w Ciebie /Pana/ wierzyła"34. Augustyn będąc jako chłopiec chorym na "okropne bóle zołądka" /tamze/, domagal stę "chrztu imię Chrystusa"/tamze/. Choć praktyka starozytnego chrześcijaństwa odkładała często udzielanie chrztu na koniec zycia, uznajac grzechy po nim popełnione za ciezsze, to Augustyn był juz wcześniej uwazany za katechumena. Gdy jego ojclec Patrycjusz powladomiz Montke o dojrzałośc1 płciowej lch syna, to ona powaznie przestrzegaza go przed cudzołóstwem ${ }^{35}$. Pogodziła sie jednak z jego konkubinatem trwającym około 15 lat $^{36}$, mimo ze usunęła go z domu za jego wojujący manicheizm37. Mniej ohmalebnym by10 zyciu Moniki usunięcie blednej matki Adeodata ${ }^{38}$, spowodonane zapewne przesądami społecznymi oraz usilne jej etarania ${ }^{39}$, by Augustyn jako profesor mógz poślubló lepiej sytuowaną córke pochodząca z tzw. dobrego domu. Na szczéscie Monika na krótko przed śmiercla doznała radoścl, ze jej syn "wzgardzimszy azczęściem doczesnym"40 stał sie sługą Bozym.

Równiez i innych dziełach Augustyna, a szczególnie w listach, znajdujemy wzmianki o trosce rodziców w sprawie wychowania swoich dzieci i mlodziezy. Jesli chodzi o dzleci to mamy dwa analogiczne teksty: 11st do Antonina $z$ lat 389/90 oraz list do Italiki z 405 roku. W pierwszym z ntch znajdujemy następujace apostrofę: "Bardzo pozdrawiam twoje dzlecie 1 zycze mu, by wzrastalo zachowujac zbawienne przykazania Pana ${ }^{41}$. W Lścle natomiast do Italiki czytamy: "Odmzajemntamy pozdrowienta twolch dzieci 1 tobie zyczymy, by one mzastały Chrystusie. Dzieci twoje juz sa p tym wieku, zo dostrzogaja jak niebezpieczne 1 szkodliwe jest przywiazanio do tego swiata.

34 Confessiones I 11, CSEL 33,15, Kublak 14 .

35 Por. Confessiones II 3, CSEL 33,32-33, Kublak 26-27.

36 Por. Confessiones IV 2, CSEL 33,64-65, Kubiak 50.

37 Por. Confessiones III 11, CSEL 33,60-61, Kubiak 46-47.

38 Por Confessiones VI 15, CSEL 33, 138, Kubiak 105.

38 Por. Confessiones VI 13, CSEL 33,136, Kubiak 104.

40 Por. Confessiones IX 10, CSEL 33,218, Kubiak 168.

41 Epistola 20,3, PL 33,87, CSEL 34,1, 48. 
Oby wíród wielkich 1 straszl1wych wstrząów chwiejna miodziez poprawiala się42.

Jeśl1 chodzi o młodziez dorastająca 1 studentów, to zwracamy tu znów uwąe na trzy listy /266,26,118/. Pierwszy z nich napisany został po $\tau$ 395, czyl1 juz po otrzymantu swięcén biskuplch, do Florentyny, Jedynej młodej dziewczyny zaszczyconej listem Augustyna. Jej ojciec, jak to wynika z tytułu nadanego córce/"eximiae"/, by dostojniki am państwowym o nieznanym nam blizej imieniu, podobnie jak nieznane jest nam imle jego zony i matki Florentyny. Augustyn odwiedziz jej rodziców /4/, choć miejsce zamieszkania tej rodziny jest nam równiez nieznane. W liście tyo wspomina /1/, ze matka Florentyny zwróciła się doń z prośba, aby pomógl jej młodej córce 1 pouczyl ja /4/ o sprawach religijnych. Florentyna była gorliwa w poboznosci 1 posiadala prawdzima mádrośćl $/ 1$. Poczatkowo, jak sam piszo, przokazywał jej swe pouczenia za pośrednictwem korespondencji z jej matka. owej pokorze nie zapowniał adresatk1, ze odpowie na kazde jej pytanie, gdyz pragnie jej pomagać jako człowlek dazzacy do doskonałości z tymi, których ma nauczać. Na zakończonie listu zgodnie ze swym dialogiem "O nauczycielu", usurajac sieblo w cleń, poucza florentyne, ze przede wszystkim oświeci ja "Nauczyclel wewnętrzny człowieka newnętrznegon ${ }^{43}$.

w latach 394-395 korespondowal równiez Augustyn z Licencjuszem, synem swego krownego 1 wlelkiego dobrodzieja Romaniana. Zaohowany list /26/ biskupa jest odpowiedzią na pismo-poemat, jakie ten mzodzleniec skierowat do niego, swego dawnego nauczyciela. w przesłanym poemacie Licencjusz ubolewa, ze ze względu na dzielaca $1 \mathrm{ch}$ odległośc /autor pozostawał Ital11, a Augustyn powrócil do Afryki/. mistrz nie moze mu juź objaśniać Warrona oraz ubolewa nad swoimi błędami $\mid$ dzledzinie stylistyki 1 metryki ${ }^{4}$. T odpowiedzi, dawny nauczyciel daje upust swej trosce z powodu literackich kiopotó owego młodszego przyjaciela. Augustyn obawia sie przy tym, ze Licencjusz wyblerze raczej kajdany namietnosci niz wigzy mądrośc

42 Ep1stola 99,3, PL 33,365, CSEL 34,2,535; por. M.E.Keenan, The 11 fo and times of St.Augustine as revealedin his letters, Washington 1935, 53-54.

43 Epistola 266,4, PL 33, 1091, CSEL 57,650 .

44 Poemat przytoczony jest w 26 l1ście św.Augustyna, PL 33, 104-106, CSEL 34, 1, 89-95. 
/2/ 1 stara się przekonać swego adresata, że usterki w metryce sa niczym porównaniu z nieładem moralnym/3/. Przestrzega również Licencjusza przed grzechami 1 zachęca, by całkowicie oddał sie Bogu /4/. Wreszcie starszy mistrz wzywa Licencjusza, by poddal sie słodkiemu jarzmu Chrystusa ${ }^{45}$. Licencjusz był chrześcijaninem, ale mniej gorliwym nız Florentyna, i nie zamierzał urzeczywistnić gorącego apelu Augustyna, by całkowicie poświecić się Bogu. Nie posladamy więcej listów biskupa do Licencjusza, ale Augustyn polecit go opiece św. Paulina z Nol1, którego stawiał młodemu męźczyźnie za wzór pójścia drogá szaleńców Bożych. Zreszta biskup z Noli przebywał bliżej Licencjusza w kampanil italskiej i dlatego mógł nim pokierować na drodze do świętości 46.

Trzeci list /118/ o charakterze duszpasterskim, jaki Augustyn sklerowal do młodego człowieka pochodzi z przełomu 410/411. Ma on szczególne znaczenie, poniewaź Augustyn prowadzi w nim młodego inteligenta ku poznaniu prawdy filozoficznej i religijnej. Ze względu na cel listu biskupa Hippony - nadajemy mu nazwe pisma duszpasterskiego. Wymieniony dokument był odpowiedzia na prośbę greckiego studenta Dioskura. Ujęty w formie prostej, więszości rękopisón nie ma nawet nazwiska adresata. Student ów przybyzz z Aleksandri1 najpierw do Rzymu, a później do Kartaginy, by doskonalić się języku 1 literaturze lacińskiej. Napotkawszy na trudności w interpretacj1 d1alogów Cycerona, zwrócił się o ich wyjaśniente do Augustyna, jako do tego, który według jego wasnych słów "ongiś te wiadomości chłopcom sprzedawał ${ }^{47}$. Augustyn mimo tłumaczenta się nawalem cięzich obowiazków duszpasterskioh wyjaśnił adresatowi niektóre zagadnienia dotyczące Boga z dialogu Cycerona "O naturze bogów 48 , zachęcając go przede wszystkim do szukania Prawdy Najwyzszej czyll Jezusa Chrystusa. Stawiaz mu przy tym za przykład niektórych neoplatónczyków。 którzy waśnie Jezusa Chrystusa uvazali za uosobiente sa-

4 Por. Eplatola 26, PL 33,103-107, CSEL 34,83-88.

46 Por. List Pqulina $\mathrm{z}$ Noll do Romanians, wtórym Jest apostroPa /4/ do Licencjusza, by słuchał "wiary Augustyna", CSEL 29, 42-52/1ist wraz z apostropa/。

47 Epistola $118,2,9$, PL 33,436, CSEL 34,2,673.

48 Tamze 4,23, PL 33,443 , CSEL $34,2,686-687$. 
mej prawdy 1 niezmiennej mądrości, jaką próbowall osiągną d ${ }^{49}$. W ten sposób Augustyn polaczył prawdę filozoficzna 1 religijną w osobie Jezusa Chrystusa, do poznania którego usilnte zachęcał owego młodego greckiego adresata.

Oto osobiste niekaznodziejskie dowody duszpasterskiej troski Augustyna o współczesna mu młodziez. W świetle naszych wywodów widać troskę rodziców o naleźyte wychowanie religijne, umystowe 1 moralne swolch dzieci, co odzwierciedla sie szczególnie w lície do Florentyny. Augustyn nie pomija kłopotów studenckich /11st 118/。 nie skąpi równieź upomnień 1 ostrzeźeńprzed duchem tego śwata /1ist 26/. Doktor Koścloła starał się, by młodzi, których prowadziz do Chrys̄tusa, albo ci, którzy do niego się zwracali, słuchali nauk wewnętrznego Nauczyciela 1 doszli do prawdzlwego szczéścia.

Ks. Wacław Eborowicz - Pelplin

\section{DE MATRIMONIO ATQUE FAMILIA \\ IN DOCTRINA ET CUIRA PASTORALI SANCTI AUGUSTINI /Suminar1 um/}

S.Augustinus, ut constat, de matrimonio, quod origo familiae est, opusculum, quod "De bono coniugali" inscripsit, composult. Inter bona, quae Deus nobis concessit, nuptiae sunt et quidem propter amicitiam /n.9/. Quae verba S. Doctoris 1llam societatem maximi momenti esse ostendunt. Inter bona matrimonil primo loco Hipponensis prolem nominat. Infantes parentes educere oportet. S. Ep1scopus etiam enitebetur, ut uterque adulescentulus et una puella bene viverent. Quorum natu maiorem Licentium, discipulum et suum amicum ad Del servittum intendere voluit, sed frustra /ep. 26/. Dioscoro natione Graeco et forte pagano respondit et ut veram sapientiam, quae in unitate cum Deo facienda positam, assequeretur, moneret $/ \mathrm{ep} \mathrm{118} / \mathrm{.}$ Florentinam, plam puellam de Magistro divino, qui intus docet. erudivit /ep. 226/.

49 Tamze 5,33, PL 33,44 , CSEI, 34,2,696-697. 